\title{
ZUR NEUAUFLAGE DER BERNER-OBERLAND-KARTE
}

\author{
VON RICHARD GROB
}

Mit einer farbigen Kartenbeilage

\begin{abstract}
Schon sind über fünfzig Jahre verstrichen, seit HermanN KüMmERLY erstmals in seinem großartigen Entwurf zur schweizerischen Schulwandkarte versuchte, das heimische Landschaftsbild in natürlichen Farben kartographisch wiederzugeben. Künstler wie Kartographen stehen heute wie damals gleichermaßen bewundernd vor dem im Alpinen Museum in Bern allen zugänglichen, einzigartigen "Gemälde», der Vorlage zu der noch immer als "Visitenkarte» der Schweiz so sehr geschätzten Schulwandkarte. Der Einwand der Bewunderer im Auslande, daß sich diese Darstellungsart nur in der Schweiz als günstig erweisen könne, ist inzwischen durch zahlreiche ähnliche Darstellungen anderer Länder längst widerlegt. Und doch, wenn wir die bei KüMMERLY \& FREY, Bern, neu erschienene "Berner-Oberland-Karte»" betrachten, müssen wir unwillkürlich beipflichten, daß sich unsere Gebirgslandschaft ganz besonders für diese Darstellungsart eignet, dáß diese hier jedenfalls den Höhepunkt ihrer Wirkung erreicht. Wie sollte uns die gewaltige Ballung von Bergen, Felsen und Gletschern des Berner Oberlandes, die hier so plastisch und klar vor uns liegt, nicht tief beeindrucken! Wie diese mächtigen Erhebungen im Südosten steil in die lange, tiefe Furche des Rhonetales abfallen, um sich jenseits nochmals in eine neue Fels- und Gletscherwelt zu erheben, die ihrerseits wieder tief in die oberitalienischen Täler abstürzt. Im Nordwesten aber sehen wir, wie sich weich und einschmeichelnd der Thunersee durch die hell aufleuchtenden Kämme der Voralpenketten in die hohe Gebirgswelt einfügt.
\end{abstract}

Wen würde nicht schon der Anblick der Karte zu einem Besuche dieses gewaltigen Teiles unserer Heimat ermuntern, der ja heute durch verschiedene Bahnen, in erster Linie die Lötschbergbahn, so erschlossen ist, daß jedermann gleichermaßen auf die Rechnung kommt. Selbst die große Zahl von Namen und Bezeichnungen, die den Wanderer orientieren und ihm über erstaunlich viele Details Auskunft geben, stören das Gesamtbild nur wenig. Heute muß ja alles benannt werden; sind doch die Menschen so glücklich, wenn sie den Dingen ihrer Umgebung einen Namen geben können, glaubend, das "Ding» damit erfaßt und seinen Geist gleichermaßen verstanden zu haben. Zwar weiß der Alpinist recht wohl, wie weit der Name, ja selbst der Anblick der Berge von einem "Verstehen» derselben entfernt ist. Und doch erinnert die Karte in schönster Weise daran, welch erhabene Welt sich hinter Worten wie Aletschhorn oder Schreckhorn verbirgt. Wenn wir auf der Karte zu ihnen hinsehen, zu ihren kalten, blauen Schatten auf den verschrundeten Gletschern, die an Schrecken und Gewalten des Berges gemahnen, um dann über die wärmeren Violettöne auf die sonnbeschienene Gletscherfläche zu blicken, oder wenn oben auf den Gräten, in den klaren Höhen uns die leuchtenden Felshänge entgegentreten, dann wird uns manches der lebendigen Wirklichkeit wieder bewußt. - Schmerzlich werden wir daran erinnert, daß, der allgemeinen Tradition entsprechend, wir immer noch die Konzession an die Nordwestbeleuchtung machen, die so manche sonnige Wand in den kühlen Schatten stellt, kaum beschienene Felsen aber im Sonnenlicht prächtig hervortreten läßt.

$\mathrm{Da}$ die Isohypsen stets in den entsprechenden Farben eingetragen sind und teilweise die Modellierung eher betonen als verwischen, läßt sich bei einer Wanderung, vom Schreckhorn hinunter über die weite Fläche des Gletschers, leicht verfolgen, wie etwa der Unteraargletscher immer enger, immer mehr von Moränenzügen und -schutt überdeckt wird und sich schließlich in das klare, blaue Wasser des Grimselsees wälzt. Wie viele schöne Wanderwege sind aber erst im eigentlichen Wandergebiet des Berner Oberlandes eingezeichnet! Allerorts laden $\mathrm{Pa}$ - und Saumpfade ein, über saftig-grüne Alpen von Tal zu Tal zu streifen. Sie genügen hier wohl auch zur Orientierung, obgleich die besondere Schönheit und Ubersichtlichkeit der Karte natürlich auf Kosten einer gewissen Schematisierung erreicht wurde. Der Alpinist bedarf ohnehin der genauesten topographischen Karten für seine "Pfade», wird aber zur Orientierung im großen gerne diese Karte benützen.

So vermag die Karte mit ihrem intensiven plastischen Relief nicht nur einen ersten Eindruck dieser gewaltigen Bergwelt zu vermitteln und uns auf unsern Wegen zu begleiten, sondern auch manche entschwundene Erinnerung wachzurufen. Mancher jugendliche Planer, rüstige Tourist wie auch alternde Genießer wird gerne zu dieser Karte greifen.

${ }^{1}$ Berner Oberland und Oberwallis. Reliefkarte mit Wanderwegen 1:75000. Überarbeitete Neuauflage 1949. Die Beilage stiftete der Geographische Verlag Kümmerly \& Frey, Bern, mit freundlicher Unterstützung durch die Direktionen der Bernischen Kraftwerke AG. und der Lötschbergbahn. 